\title{
PEMILIHAN UNIVERSITAS FAVORIT SISWA MADRASAH ALIYAH AL-ISLAMIYAH DI JAKARTA BARAT DENGAN MENGGUNAKAN METODE MARKOV CHAIN
}

\author{
Adi Teguh Suprapto ${ }^{1}$ \\ Jurusan Manajemen, Bina Nusantara University \\ J1. KH. Syahdan No. 9, Jakarta Barat, Indonesia, 11480 \\ aditeguhs992@gmail.com \\ Aris Setiyarini ${ }^{2}$ \\ Jurusan Managemen, STIE Bisnis Indonesia, Jakarta Barat, Indonesia, 11560 \\ setiyariniaris@yahoo.com \\ Haryadi Sarjono ${ }^{3}$ \\ Jurusan Manajemen, Bina Nusantara University \\ Jl. KH. Syahdan No. 9, Jakarta Barat, Indonesia, 11480 \\ haryadisarjono@yahoo.com
}

\begin{abstract}
The purpose of this study was to determine the amount of transfer of interest at class XII student at Madrasah Aliyah Al-Islamiyah in West Jakarta to five favorite namely UIN, BINUS, UNJ, UI and UMN in the next period and to discover the source of reference selection and assessment of student on the fifth university. Sample consists of 39 class XII student at Madrasah Aliyah Al-Islamiyah in West Jakarta, with the methods and type of survey of survey research is descriptive research. The result is a prediction of the five university in order in the next period of $(0.5135,0.1008,0.2077,0.078,0.1)$ and the selection of a reference source that is 0.62 of brand image, 0.583 of the promotional events, 0.582 from friends and 0.54 of the university security. Largest market share held by UIN enthusiasts of $51 \%$, while the smallest market share owned by UI enthusiasts is equal to $8 \%$.
\end{abstract}

Keywords: Markov Chain, Favorite, Madrasah Aliyah Al-Islamiyah (MA), West Jakarta, University ABSTRAK

Tujuan penelitian ini adalah untuk mengetahui besarnya perpindahan, peminatan pelajar kelas XII Madrasah Aliyah Al-Islamiyah di Jakarta Barat terhadap lima universitas favorit, yaitu UIN, BINUS, UNJ, UI dan UMN pada periode berikutnya dan untuk mengetahui sumber referensi pemilihan dan penilaian pelajar terhadap kelima universitas tersebut. Sampelnya terdiri dari 39 pelajar kelas XII Madrasah Aliyah Al-Islamiyah di Jakarta Barat, dengan metode penelitian adalah survei dan jenis penelitiannya deskriptif. Hasilnya adalah prediksi peminatan kelima universitas secara berurutan pada periode berikutnya sebesar $(0.5135,0.1008,0.2077,0.078,0.1)$ dan sumber referensi pemilihan, yaitu 0.62 responden memlilih universitas favorit karena citra universitas (brand image), 0.583 responden memperoleh referensi dari event promosi yang dilakukan oleh universitas tersebut, 0.582 responden memperoleh referensi dari teman, dan 0.54 responen memilih universitas favorit karena keamanan universitas. Pangsa pasar terbesar dimiliki oleh peminat UIN sebesar 51\%, sedangkan pangsa pasar terkecil dimiliki oleh peminat UI yaitu sebesar $8 \%$.

Kata Kunci: Markov Chain, Favorit, Madrasah Aliyah Al-Islamiyah (MA), Jakarta Barat, Universitas.

\section{PENDAHULUAN}

Pendidikan tidaklah hanya sekedar transfer ilmu pengetahuan (transfer of knowledge), akan tetapi tujuan pendidikan sesungguhnya adalah untuk menciptakan pribadi yang memiliki sikap dan kepribadian yang positif. Perguruan tinggi yang akan melahirkan para sarjana pun saat ini tidak kalah tumbuh pesat, tercatat ratusan perguruan tinggi yang ada di Indonesia yang menawarkan beragam program studi dan fasilitas yang menjanjikan.

Universitas adalah suatu institusi pendidikan tinggi dan penelitian yang memberikan gelar akademik dalam berbagai bidang, sedangkan kaum pelajar menengah atas merupakan salah satu target 
pasar yang memiliki potensi besar dalam memberikan profit bagi universitas. Tidak heran jika banyak universitas yang berlomba-lomba dalam meraih pangsa pasar yang ada. Hal ini dilakukan dengan berbagai strategi pemasaran seperti promosi yang dilakukan baik melalui media cetak, media elektronik, dan terutama pemasaran langsung ke sekolah-sekolah, yang ditujukan bagi kaum pelajar sekolah menengah atas yang ingin melanjutkan pendidikan ke jenjang perguruan tinggi.

Madrasah Aliyah (MA) adalah jenjang pendidikan menengah pada pendidikan formal di Indonesia yang setara dengan Sekolah Menengah Atas (SMA). Madrasah Aliyah (MA) pengelolaannya dilakukan oleh Kementrian Agama dan kurikulum Madrasah Aliyah sama dengan kurikulum Sekolah Menengah Atas, akan tetapi Madrasah Aliyah lebih banyak belajar mengenai pendidikan agama islam. Lulusan Madrasah Aliyah dapat melanjutkan pendidikan ke perguruan tinggi umum, perguruan tinggi islam, atau langsung bekerja.

Salah satu Madrasah Aliyah Swasta (MAS) di Jakarta Barat yang dekat dengan universitas besar adalah Madrasah Aliyah Al-Islamiyah. Banyak referensi universitas favorit yang dekat dengan Madrasah Aliyah tersebut, antara lain Universitas Trisakti, Universitas Bina Nusantara, dan Universitas Tarumanagara. Banyak faktor yang membuat siswa kelas XII untuk memilih universitas favoritnya, ada juga beberapa siswa yang memilih universitas lain selain universitas tersebut meski jaraknya relatif jauh dari sekolah Madrasah Aliyah AlIslamiyah, antara lain Universitas Negeri Jakarta, Universitas Islam Negeri, Universitas Indonesia, dan Universitas Multimedia Nusantara. Perpindahan pelajar dalam memilih universitas yang paling disenangi selama kurun waktu tertentu akan menambah kerumitan dalam pengukuran, di mana teknik Markov Chain dapat digunakan untuk menanalisis penilaian pangsa pasar dan perpindahan merek tersebut.

\section{TINJAUAN PUSTAKA} Pangsa Pasar (Market Share)

Menurut Irianto (2015), "Pangsa pasar merupakan besarnya bagian atau luasnya total pasar yang dapat dikuasai oleh suatu perusahaan yang biasanya dinyatakan dengan persentase (\%). Pangsa pasar ini dapat dipecah-pecah menurut wilayah politis, kawasan geografis yang lebih besar, ukuran, pelanggan, tipe pelanggan, dan teknologinya. Menurut Kotler dalam Irianto (2015), pangsa pasar dapat mengukur seberapa besar porsi penjualan perusahaan di pasaran dan seberapa besar porsi perusahaan dengan merek tertentu.

Berdasarkan pengertian di atas, maka dapat disimpulkan bahwa pangsa pasar adalah persentase penjualan dalam satu pasar tertentu yang dikuasai oleh perusahaan, merek, atau produk tertentu. 


\section{Merek}

Menurut Kotler dan Armstrong dalam Herdiana (2015:82), "Merek adalah nama istilah benda, lambang atau desain atau kombinasi dari semua ciri yang memperlihatkan identitas produk atau jasa satu produk atau sekelompok penjual dan membedakan itu dari produk pesaing”.

Menurut American Marketing Association (AMA) dalam Tjiptono (2015:187), merek sebagai nama, istilah, tanda, simbol atau desain, atau kombinasi di antaranya, yang dimaksudkan untuk mengidentifikasi barang dan jasa dari satu penjual atau sekelompok penjual dan membedakannya dari barang dan jasa para pesaingnya.

\section{Promosi}

Menurut Adam (2015:36), "Promosi penjualan merupakan kegiatan yang dilakukan dengan tujuan untuk menyediakan insentif guna peningkatan penjualan”. Menurut William J. Stanton dalam Herdiana (2015:155), "Promosi adalah salah satu dalam bauran pemasaran yang digunakan untuk memberitahukan, membujuk, dan mengingatkan tentang produk perusahaan". Berdasarkan pengertian tersebut dapat disimpulkan bahwa promosi adalah suatu bauran pemasaran yang digunakan untuk meningkatkan nilai pelanggan atau membangun ekuitas merek dalam ingatan pelanggan.

\section{Markov Chain}

Menurut Render et al dalam Sarjono (2010:200), “Analisis markov merupakan sebuah teknik yang berhubungan dengan probabilitas akan state di masa mendatang dengan menganalisa probabilitas saat ini. Teknik ini memiliki beragam aplikasi dalam dunia bisnis, diantaranya analisis pangsa pasar, prediksi kerugian, prediksi penerimaan mahasiswa baru di universitas, dan menentukan apakah sebuah mesin akan mengalami kerusakan di masa mendatang”.

Menurut Levin et al dalam Sarjono (2010:200), “Analisa markov merupakan sebuah metode dalam menganalisa perilaku saat ini dari beberapa variabel dengan tujuan untuk memprediksi perilaku dari variabel yang sama di masa mendatang".

\section{Probabilitas State (Probabilities State)}

Menurut Render et al dalam Nursanti, dkk (2010), state digunakan untuk mengidenifikasi seluruh kondisi yang mungkin dari suatu proses atau sistem. Sarjono (2010:200), menyatakan bahwa setelah state dari sistem atau proses yang akan diteliti telah diidentifikasi, langkah selanjutnya adalah menentukan probabilitas sistem berada dalam state tertentu dengan menggunakan vektor probabilitas state.

$\pi$ (i) $=$ Vektor dari probabilitas state untuk periode $\mathrm{i}$

Dimana :

$$
=(\pi 1, \pi 2, \pi 3, \ldots, \pi \mathrm{n})
$$

$$
\mathrm{n}=\text { jumlah state }
$$


$\pi 1, \pi 2, \pi 3, \ldots, \pi \mathrm{n}=$ probabilitas berada dalam state ke-1, state ke-2, state ke-n

\section{Matriks Transisi Probabilitas}

Sarjono (2010:201), menyatakan bahwa matriks transisi probabilitas memungkinkan untuk melalukan perhitungan probabilitas state di masa mendatang berdasarkan pada state saat ini.

Pij = probabilitas kondisi berada dalam state $\mathrm{j}$ di masa mendatang berdasarkan state i saat ini.

Menurut Noer (2010:171-172), konsep rantai markov mengacu pada rantai perubahan tiap kondisi yang ada dari satu periode ke periode berikutnya. Misalkan, kondisi tanah pertanian pada suatu periode ada tiga kemungkinan: subur, kurang subur, dan kering. Untuk periode berikutnya, kondisi tanah pertanian tersebut dapat saja berubah ke subur, kurang subur, atau kering. Ada atau tidaknya perubahan dari satu kondisi ke kondisi lainnya dapat digambarkan dalam matriks berikut:

1. Sekarang subur: masa mendatang mungkin tetap subur, menjadi kurang subur, atau menjadi kering.

2. Sekarang kurang subur: masa mendatang mungkin menjadi subur, tetap kurang subur, atau menjadi kering.

3. Sekarang kering: masa mendatang mungkin menjadi subur, menjadi kurang subur, atau tetap kering.

Bentuk matriks probabilitasnya dapat dilihat pada tabel 2.1. sebagai berikut:
Tabel 1 Matriks Probabilitas

\begin{tabular}{|c|c|c|c|}
\hline \multirow{2}{*}{ Periode i } & \multicolumn{3}{|c|}{ Periode $\mathbf{j}$} \\
& \multicolumn{3}{|c|}{} \\
\cline { 2 - 4 } & $\mathbf{1}$ & $\mathbf{2}$ & $\mathbf{3}$ \\
\hline 1 & P11 & P12 & P13 \\
\hline 2 & P21 & P22 & P23 \\
\hline 3 & P31 & P32 & P33 \\
\hline
\end{tabular}

Sumber: Noer (2010:171)

Berikut ini adalah gambar 2.2. rantai markov:

\section{Gambar 1 Rantai Markov}

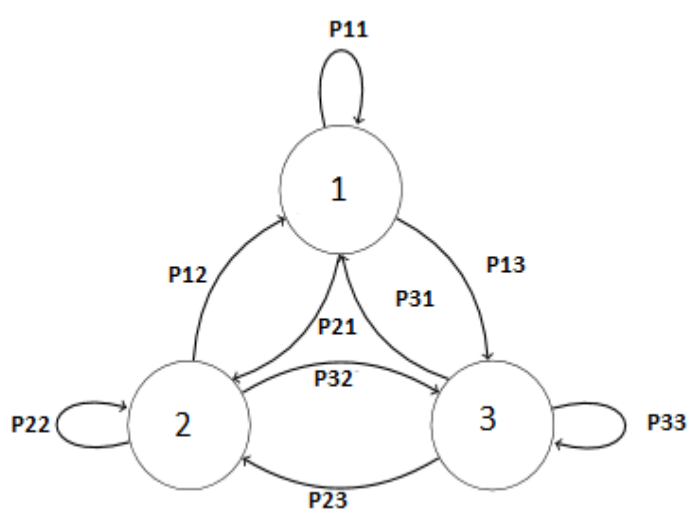

Sumber: Noer (2010:172)

\section{METODE PENELITIAN}

Menurut Sugiyono (2014:2), "Metode penelitian pada dasarnya merupakan cara ilmiah untuk mendapatkan data dengan tujuan dan kegunaan tertentu”. 
Tabel 2

\section{Operasional Variabel}

\begin{tabular}{|l|l|l|c|}
\hline $\begin{array}{c}\text { Variabel/ } \\
\text { Sub } \\
\text { Variabel }\end{array}$ & $\begin{array}{c}\text { Konsep } \\
\text { Variabel/Sub } \\
\text { Variabel }\end{array}$ & Indikator & $\begin{array}{c}\text { Skala } \\
\text { Pengukuran }\end{array}$ \\
\hline $\begin{array}{l}\text { Penelitian } \\
\text { universitas } \\
\text { oleh pelajar } \\
\text { dalam tiga } \\
\text { periode. }\end{array}$ & $\begin{array}{l}\text { Pemilihan } \\
\text { universitas } \\
\text { dibanding-kan } \\
\text { dengan }\end{array}$ & $\begin{array}{c}\text { 1. Universitas } \\
\text { yang } \\
\text { diminati } \\
\text { pada }\end{array}$ & Nominal \\
& universitas & periode & \\
pertama. & \\
& tersebut & 2. Universitas & \\
& & yang & \\
& & diminati & \\
& & pada & \\
& & kedua. & \\
Penilaian & Penilaian yang & Alasan: & Nominal \\
pelajar & diberikan oleh & 1. Fasilitas & \\
terhadap & pelajar atas & 2. Lokasi & \\
universitas & pemilihan & 3. Biaya Kuliah & \\
yang ada & universitas & 4. Kualitas & \\
& yang ada. & Pendidikan & \\
& & 5. Promosi & \\
& & 6. Referensi & \\
& & 7. Visi dan Misi & \\
\hline
\end{tabular}

Sumber: Hasil Pengolahan Penulis (2016)

\section{Metode Pengumpulan Data}

Tabel 3

Desain Penelitian

\begin{tabular}{|c|c|c|l|l|}
\hline $\begin{array}{c}\text { Tujuan } \\
\text { Peneli- } \\
\text { tian }\end{array}$ & $\begin{array}{c}\text { Jenis } \\
\text { Peneli- } \\
\text { tian }\end{array}$ & $\begin{array}{c}\text { Metode } \\
\text { Peneli- } \\
\text { tian }\end{array}$ & \multicolumn{1}{|c|}{$\begin{array}{c}\text { Unit } \\
\text { Analisis }\end{array}$} & $\begin{array}{c}\text { Horizo } \\
\text { n } \\
\text { Waktu }\end{array}$ \\
\hline (T-1) & $\begin{array}{c}\text { Deskrip } \\
\text { tif }\end{array}$ & Survei & $\begin{array}{l}\text { Individu: Siswa } \\
\text { MA Al- } \\
\text { Islamiyah di } \\
\text { Jakarta Barat }\end{array}$ & $\begin{array}{l}\text { Longi- } \\
\text { tudinal }\end{array}$ \\
\hline (T-2) & $\begin{array}{c}\text { Deskrip } \\
\text { tif }\end{array}$ & Survei & $\begin{array}{l}\text { Individu: Siswa } \\
\text { MA Al- } \\
\text { Islamiyah di } \\
\text { Jakarta Barat }\end{array}$ & $\begin{array}{l}\text { Longit } \\
\text { udinal }\end{array}$ \\
\hline (T-3) & $\begin{array}{c}\text { Deskrip } \\
\text { tif }\end{array}$ & Survei & $\begin{array}{l}\text { Individu: Siswa } \\
\text { MA Al- } \\
\text { Islamiyah di } \\
\text { Jakarta Barat }\end{array}$ & $\begin{array}{l}\text { One } \\
\text { Shoot- } \\
\text { Cross } \\
\text { Section }\end{array}$ \\
\hline (T-4) & $\begin{array}{c}\text { Deskrip } \\
\text { tif }\end{array}$ & Survei & $\begin{array}{l}\text { Individu: Siswa } \\
\text { MA Al- }\end{array}$ & $\begin{array}{l}\text { One } \\
\text { Shoot- } \\
\text { Cross } \\
\text { Islamiyah di } \\
\text { Jakarta Barat }\end{array}$ \\
& & & Section \\
\hline
\end{tabular}

Sumber: Hasil Pengolahan Penulis (2016)

Teknik Pengumpulan Data

Teknik pengumpulan data merupakan cara yang dilakukan peneliti untuk mengungkap atau menjaring informasi kuantitatif dari responden sesuai lingkup penelitian.

Tabel 4

Data dan Sumber Data Penelitian

\begin{tabular}{|c|c|c|c|}
\hline $\begin{array}{c}\text { Tujuan } \\
\text { Penelitian }\end{array}$ & $\begin{array}{c}\text { Data } \\
\text { Penelitian }\end{array}$ & $\begin{array}{c}\text { Jenis } \\
\text { Data } \\
\text { Penelitian }\end{array}$ & $\begin{array}{l}\text { Sumber Data } \\
\text { Penelitian }\end{array}$ \\
\hline$(\mathrm{T}-1)$ & $\begin{array}{l}\text { Penilaian } \\
\text { pelajar } \\
\text { terhadap } \\
\text { universitas } \\
\text { swasta } \\
\text { yang } \\
\text { dipilih. }\end{array}$ & Kuantitatif & $\begin{array}{l}\text { Data primer dari } \\
\text { kuisioner siswa } \\
\text { Madrasah Aliyah } \\
\text { Al-Islamiyah di } \\
\text { Jakarta Barat. }\end{array}$ \\
\hline$(\mathrm{T}-2)$ & $\begin{array}{l}\text { Penilaian } \\
\text { universitas }\end{array}$ & Kuantitatif & $\begin{array}{l}\text { Data primer dari } \\
\text { kuisioner siswa } \\
\text { Madrasah Aliyah } \\
\text { Al-Islamiyah di } \\
\text { Jakarta Barat. }\end{array}$ \\
\hline$(\mathrm{T}-3)$ & $\begin{array}{l}\text { Sumber } \\
\text { referensi } \\
\text { pemilihan } \\
\text { universitas }\end{array}$ & Kualitatif & $\begin{array}{l}\text { Data primer dari } \\
\text { kuisioner siswa } \\
\text { Madrasah Aliyah } \\
\text { Al-Islamiyah di } \\
\text { Jakarta Barat. }\end{array}$ \\
\hline$(\mathrm{T}-4)$ & $\begin{array}{l}\text { Penilaian } \\
\text { universitas }\end{array}$ & Kualitatif & $\begin{array}{l}\text { Data primer dari } \\
\text { kuisioner siswa } \\
\text { Madrasah Aliyah } \\
\text { Al-Islamiyah di } \\
\text { Jakarta Barat. }\end{array}$ \\
\hline
\end{tabular}

Sumber: Hasil Pengolahan Penulis (2016)

\section{HASIL DAN PEMBAHASAN}

\section{Tabel 5}

Jumlah Pemilih, Probabilitas dan Proporsi

Berbagai Universitas pada Madrasah

Aliyah Al-Islamiyah di Jakarta Barat (Kuesioner 1)

\begin{tabular}{|c|c|c|c|c|c|}
\hline No & Ket & State & $\begin{array}{c}\text { Jumlh } \\
\text { Resp }\end{array}$ & $\begin{array}{l}\text { Proba } \\
\text { bilitas }\end{array}$ & $\begin{array}{c}\text { Proporsi } \\
(\%)\end{array}$ \\
\hline 1 & $\begin{array}{c}\text { Univ. Islam } \\
\text { Negeri }\end{array}$ & State 1 & 15 & 0.38 & 38 \\
\hline 2 & $\begin{array}{c}\text { IAIN } \\
\text { Serang } \\
\end{array}$ & State 2 & 1 & 0.02 & 2 \\
\hline 3 & Kerja & State 3 & 7 & 0.18 & 18 \\
\hline 4 & $\begin{array}{l}\text { Univ. Bina } \\
\text { Nusantara }\end{array}$ & State 4 & 4 & 0.10 & 10 \\
\hline 5 & $\begin{array}{l}\text { Univ. } \\
\text { Negeri } \\
\text { Jakarta }\end{array}$ & State 5 & 3 & 0.08 & 8 \\
\hline 6 & BSI & State 6 & 1 & 0.02 & 2 \\
\hline 7 & $\begin{array}{c}\text { Univ. } \\
\text { Indonesia }\end{array}$ & State 7 & 3 & 0.08 & 8 \\
\hline 8 & STAN & State 8 & 1 & 0.03 & 3 \\
\hline 9 & $\begin{array}{c}\text { Univ. } \\
\text { Multimedia } \\
\text { Nusantara }\end{array}$ & State 9 & 2 & 0.05 & 5 \\
\hline 10 & $\begin{array}{c}\text { Univ. } \\
\text { Moestopo }\end{array}$ & $\begin{array}{c}\text { State } \\
10\end{array}$ & 1 & 0.03 & 3 \\
\hline 11 & $\begin{array}{l}\text { Univ. Esa } \\
\text { Unggul }\end{array}$ & $\begin{array}{c}\text { State } \\
11\end{array}$ & 1 & 0.3 & 3 \\
\hline \multicolumn{3}{|c|}{ Total } & 39 & 1.00 & 100 \\
\hline
\end{tabular}

Sumber: Hasil Pengolahan Penulis (2016)

Keterangan:

State 1 - Universitas Islam Negeri

$$
5 / 39=0.38=38 \%
$$


State 2 - IAIN Serang

$$
1 / 39=0.02=2 \%
$$

State 3 - Kerja

$$
7 / 39=0.18=18 \%
$$

State 4 - Universitas Bina Nusantara

$$
4 / 39=0.10=10 \%
$$

State 5 - Universitas Negeri Jakarta

$$
3 / 39=0.08=8 \%
$$

State 6 - Universitas BSI

$$
1 / 39=0.03=3 \%
$$

State 7 - Universitas Indonesia

$$
3 / 39=0.08=8 \%
$$

State 8 - STAN

$$
1 / 39=0.03=3 \%
$$

State 9 - Universitas Multimedia Nusantara

$$
2 / 39=0.05=5 \%
$$

State 10 - Universitas Moestopo

$$
1 / 39=0.03=3 \%
$$

State 11- Universitas Esa Unggul

$$
1 / 39=0.03=3 \%
$$

dimana:

$\pi(1)=(0.38,0.02,0.18,0.10,0.08,0.02$, $0.08,0.03,0.05,0.03,0.03)$

$(1)=$ vector probabilitas state kelima universitas untuk periode 1

$\pi_{1}=0.38=$ Probabilitas satu orang yang memilih UIN, state 1

$\pi_{2}=0.02=$ Probabilitas satu orang yang memilih IAIN Serang, state 2

$\pi_{3}=0.18=$ Probabilitas satu orang yang memilih kerja, state 3

$\pi_{4}=0.10=$ Probabilitas satu orang yang memilih BINUS, state 4

$\pi_{5}=0.08=$ Probabilitas satu orang yang memilih UNJ, state 5

$\pi_{6}=0.02=$ Probabilitas satu orang yang memilih BSI, state 6

$\pi_{7}=0.08=$ Probabilitas satu orang yang memilih UI, state 7

$\pi_{8}=0.03=$ Probabilitas satu orang yang memilih STAN, state 8

$\pi_{9}=0.05=$ Probabilitas satu orang yang memilih UMN, state 9

$\pi_{10}=0.03=$ Probabilitas satu orang yang memilih Universitas Moestopo, state 10 $\pi_{11}=0.03=$ Probabilitas satu orang yang memilih Universitas Esa Unggul, state 11

Berdasarkan hasil kuesioner tersebut, hanya dipilih lima universitas favorit yang paling banyak diminati oleh siswa Madrasah Aliyah Al-Islamiyah di Jakarta Barat, yaitu Universitas Islam Negeri (UIN), Universitas Bina Nusantara (UBinus), Universitas Negeri Jakarta (UNJ), Universitas Indonesia (UI), dan Universitas Multimedia Nusantara (UMN).

Tabel 6

Jumlah Pemilih, Probabilitas dan

Proporsi ke-5 Universitas Favorit pada Madrasah Aliyah Al-Islamiyah di Jakarta Barat (Kuesioner 2)

\begin{tabular}{|c|l|c|c|c|c|}
\hline No & $\begin{array}{l}\text { Nama } \\
\text { Universitas }\end{array}$ & State & $\begin{array}{c}\text { Jumlh } \\
\text { respd }\end{array}$ & $\begin{array}{c}\text { Proba- } \\
\text { bilitas }\end{array}$ & $\begin{array}{c}\text { Proporsi } \\
(\%)\end{array}$ \\
\hline 1 & $\begin{array}{l}\text { Univ. Islam } \\
\text { Negeri }\end{array}$ & State 1 & 16 & 0.41 & 41 \\
\hline 2 & $\begin{array}{l}\text { Univ. Bina } \\
\text { Nusantara }\end{array}$ & State 2 & 2 & 0.05 & 5 \\
\hline 3 & $\begin{array}{l}\text { Univ. } \\
\text { Negeri } \\
\text { Jakarta }\end{array}$ & State 3 & 12 & 0.31 & 31 \\
\hline 4 & $\begin{array}{l}\text { Univ. } \\
\text { Indonesia }\end{array}$ & State 4 & 5 & 0.13 & 13 \\
\hline 5 & $\begin{array}{l}\text { Univ. } \\
\text { Multimedia } \\
\text { Nusantara }\end{array}$ & State 5 & 4 & 0.10 & 10 \\
\hline \multicolumn{7}{|l|}{ Total } & $\mathbf{3 9}$ & $\mathbf{1 . 0 0}$ & $\mathbf{1 0 0}$ \\
\hline
\end{tabular}

Sumber: Hasil Pengolahan Penulis (2016)

Keterangan:

State 1 - Universitas Islam Negeri

$$
16 / 39=0.41=41 \%
$$

State 2 - Universitas Bina Nusantara

$$
2 / 39=0.05=5 \%
$$

State 3 - Universitas Negeri Jakarta

$$
12 / 39=0.31=31 \%
$$

State 4 - Universitas Indonesia

$$
5 / 39=0.13=13 \%
$$

State 5 - Universitas Multimedia Nusantara $4 / 39=0.10=10 \%$

dimana:

$\pi(1)=(0.41,0.05,0.31,0.13,0.10)$

$(1)=$ vector probabilitas state kelima universitas untuk periode 2

$\pi_{1}=0.41=$ probabilitas satu orang yang memilih UIN, state 1

$\pi_{2}=0.05=$ probabilitas satu orang yang memilih BINUS, state 2

$\pi_{3}=0.31=$ probabilitas satu orang yang memilih UNJ, state 3

$\pi_{4}=0.13=$ probabilitas satu orang yang memilih UI, state 4 
$\pi_{5}=0.10=$ probabilitas satu orang yang memilih UMN, state 5

Tabel 7

Jumlah Pemilih, Probabilitas dan Proporsi ke-5 Universitas Favorit pada Madrasah Aliyah Al-Islamiyah di Jakarta Barat (Kuesioner 3)

\begin{tabular}{|c|l|c|c|c|c|}
\hline No & $\begin{array}{c}\text { Nama } \\
\text { Univ. }\end{array}$ & State & $\begin{array}{c}\text { Jumlh } \\
\text { resp }\end{array}$ & $\begin{array}{c}\text { Proba- } \\
\text { bilitas }\end{array}$ & $\begin{array}{c}\text { Proporsi } \\
(\%)\end{array}$ \\
\hline 1 & $\begin{array}{l}\text { Univ. Islam } \\
\text { Negeri }\end{array}$ & State 1 & 20 & 0.51 & 51 \\
\hline 2 & $\begin{array}{l}\text { Univ. Bina } \\
\text { Nusantara }\end{array}$ & State 2 & 4 & 0.10 & 10 \\
\hline 3 & $\begin{array}{l}\text { Univ. Negri } \\
\text { Jakarta }\end{array}$ & State 3 & 8 & 0.21 & 21 \\
\hline 4 & $\begin{array}{l}\text { Univ. } \\
\text { Indonesia }\end{array}$ & State 4 & 3 & 0.08 & 8 \\
\hline 5 & $\begin{array}{l}\text { Univ. } \\
\text { Multimedia } \\
\text { Nusantara }\end{array}$ & State 5 & 4 & 0.10 & 10 \\
\hline \multicolumn{7}{|l|}{ Total } \\
\hline
\end{tabular}

Sumber: Hasil pengolahan penulis, (2016)

Keterangan:

State 1 - Universitas Islam Negeri

$$
20 / 39=0.51=51 \%
$$

State 2 - Universitas Bina Nusantara

$$
4 / 39=0.10=10 \%
$$

State 3 - Universitas Negeri Jakarta

$$
8 / 39=0.21=21 \%
$$

State 4 - Universitas Indonesia

$$
3 / 39=0.08=8 \%
$$

State 5 - Universitas Multimedia Nusantara

$$
4 / 39=0.10=10 \%
$$

dimana:

$\pi(1)=(0.49,0.10,0.21,0.10,0.10)$

$(1)=$ vector probabilitas state kelima universitas untuk periode 2

$\pi_{1}=0.49=$ probabilitas satu orang yang memilih UIN, state 1

$\pi_{2}=0.10=$ probabilitas satu orang yang memilih BINUS, state 2 $\pi_{3}=0.21=$ probabilitas satu orang yang memilih UNJ, state 3

$\pi_{4}=0.10=$ probabilitas satu orang yang memilih UI, state 4

$\pi_{5}=0.10=$ probabilitas satu orang yang memilih UMN, state 5

Penelitian pada periode ketiga menunjukkan adanya perpindahan dari universitas yang satu ke universitas yang lain. Perpindahan merek adalah gejala yang umum terjadi di kalangan konsumen.

Tabel 8

\begin{tabular}{|c|c|c|c|c|c|}
\hline No & $\begin{array}{l}\text { Nama } \\
\text { Univ. }\end{array}$ & $\begin{array}{l}\text { Jumlah } \\
\text { Univ. } \\
\text { Sebelum } \\
\text { (Priode } \\
\text { 2) }\end{array}$ & $\begin{array}{c}\text { Pero } \\
\text { lehan } \\
\text { Konsu } \\
\text { men }\end{array}$ & $\begin{array}{c}\text { Kehila } \\
\text { ngan } \\
\text { Konsu } \\
\text { men }\end{array}$ & $\begin{array}{c}\text { Jumlah } \\
\text { Univ. } \\
\text { Saat ini } \\
\text { (Priode } \\
\text { 3) }\end{array}$ \\
\hline 1 & $\begin{array}{l}\text { Univ. Islam } \\
\text { Negeri }\end{array}$ & 16 & 4 & - & 20 \\
\hline 2 & $\begin{array}{l}\text { Univ. Bina } \\
\text { Nusantara }\end{array}$ & 2 & 2 & - & 4 \\
\hline 3 & $\begin{array}{l}\text { Univ. } \\
\text { Negeri } \\
\text { Jakarta }\end{array}$ & 12 & - & 4 & 8 \\
\hline 4 & $\begin{array}{l}\text { Univ. } \\
\text { Indonesia }\end{array}$ & 5 & - & 2 & 3 \\
\hline 5 & $\begin{array}{l}\text { Univ. } \\
\text { Multimedia } \\
\text { Nusantara }\end{array}$ & 4 & - & - & 4 \\
\hline \multicolumn{2}{|r|}{ Total } & 39 & 6 & 9 & 39 \\
\hline
\end{tabular}

Jumlah Perolehan dan Kehilangan Konsumen ke-5 Universitas Favorit Siswa Madrasah Aliyah Al-Islamiyah di Jakarta Barat

Sumber: Hasil pengolahan penulis (2016)

Perpindahan pangsa pasar kelima universitas favorit siswa Madrasah Aliyah Al-Islamiyah di Jakarta Barat dapat dilihat secara lebih rinci pada tabel 9 sebagai berikut: 
Tabel 9

Perpindahan Pangsa Pasar ke-5

Universitas favorit siswa Madrasah Aliyah

Al-Islamiyah di Jakarta Barat

\begin{tabular}{|c|c|c|}
\hline No. & $\begin{array}{c}\text { Perpindahan Universitas Favorit Siswa } \\
\text { Madrasah Aliyah Al-Islamiyah di Jak. Bar }\end{array}$ & Jumlah \\
\hline 1 & UIN ke UIN & 16 \\
\hline 2 & UIN ke BINUS & 0 \\
\hline 3 & UIN ke UNJ & 0 \\
\hline 4 & UIN ke UI & 0 \\
\hline 5 & UIN ke UMN & 0 \\
\hline 6 & BINUS ke UIN & 0 \\
\hline 7 & BINUS ke BINUS & 2 \\
\hline 8 & BINUS ke UNJ & 0 \\
\hline 9 & BINUS ke UI & 0 \\
\hline 10 & BINUS ke UMN & 0 \\
\hline 11 & UNJ ke UIN & 3 \\
\hline 12 & UNJ ke BINUS & 1 \\
\hline 13 & UNJ ke UNJ & 8 \\
\hline 14 & UNJ ke UI & 0 \\
\hline 15 & UNJ ke UMN & 0 \\
\hline 16 & UI ke UIN & 1 \\
\hline 17 & UI ke BINUS & 1 \\
\hline 18 & UI ke UNJ & 0 \\
\hline 19 & UI ke UI & 3 \\
\hline 20 & UI ke UMN & 0 \\
\hline 21 & UMN ke UIN & 0 \\
\hline 22 & UMN ke BINUS & 0 \\
\hline 23 & UMN ke UNJ & 0 \\
\hline 24 & UMN ke UI & 0 \\
\hline 25 & UMN ke UMN & 4 \\
\hline \multicolumn{2}{|r|}{ Total } & 39 \\
\hline
\end{tabular}

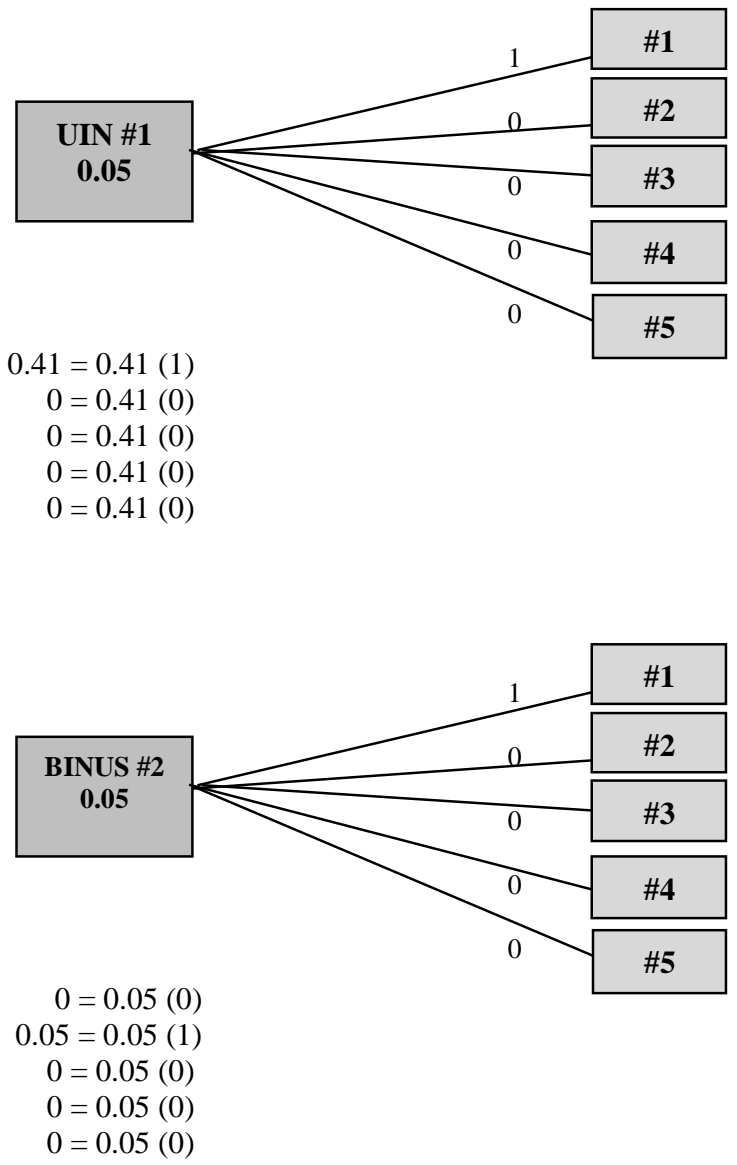

Sumber: Hasil Pengolahan Penulis (2016)

Berdasarkan perpindahan pangsa pasar

yang ada, diperoleh hasil yang menujukkan

probabilitas state ke-5 universitas favorit

yang dipilih oleh siswa Madrasah Aliyah

Al-Islamiyah di Jakarta Barat, seperti

berikut:

Tabel 10

Probabilitas State ke-5 Universitas Favorit Siswa Madrasah Aliyah Al-Islamiyah di Jakarta Barat

\begin{tabular}{|c|c|l|c|}
\hline No. & State & $\begin{array}{c}\text { Nama } \\
\text { Universitas }\end{array}$ & Probabilitas State \\
\hline 1 & State 1 & UIN & $16 / 39=0.41=41 \%$ \\
\hline 2 & State 2 & BINUS & $2 / 39=0.05=5 \%$ \\
\hline 3 & State 3 & UNJ & $12 / 39=0.31=31 \%$ \\
\hline 4 & State 4 & UI & $5 / 39=0.13=13 \%$ \\
\hline 5 & State 5 & UMN & $4 / 39=0.10=10 \%$ \\
\hline
\end{tabular}

Sumber: Hasil Pengolahan Penulis (2016)

Gambar 2

Diagram Pohon ke-5 Universitas Favorit Siswa Madrasah Aliyah Al-Islamiyah di Jakarta Barat

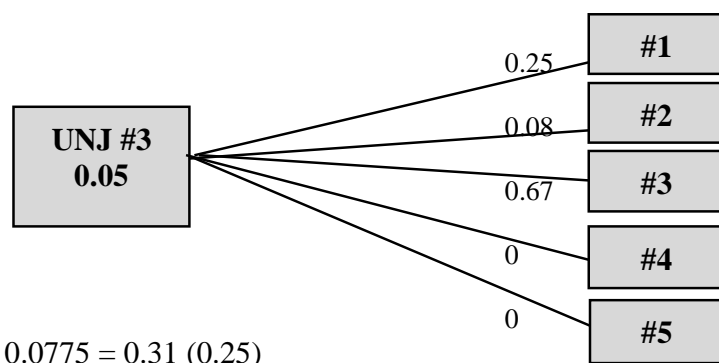

$0.0248=0.31(0.08)$

$0.2077=0.31(0.67)$

$0=0.31(0)$

$0=0.31(0)$

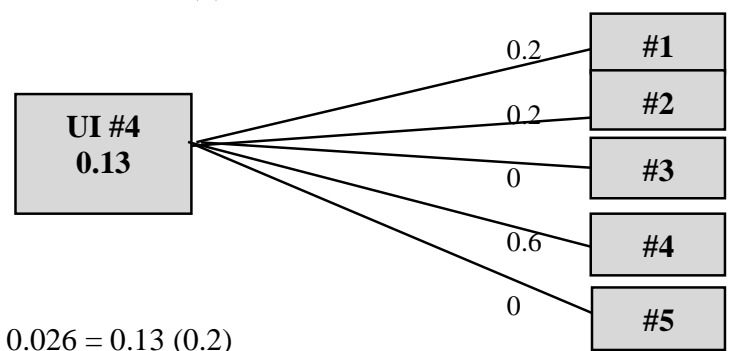

$0.026=0.13(0.2)$

$0=0.13(0)$

$0.078=0.13(0.6)$

$0=0.13(0)$ 


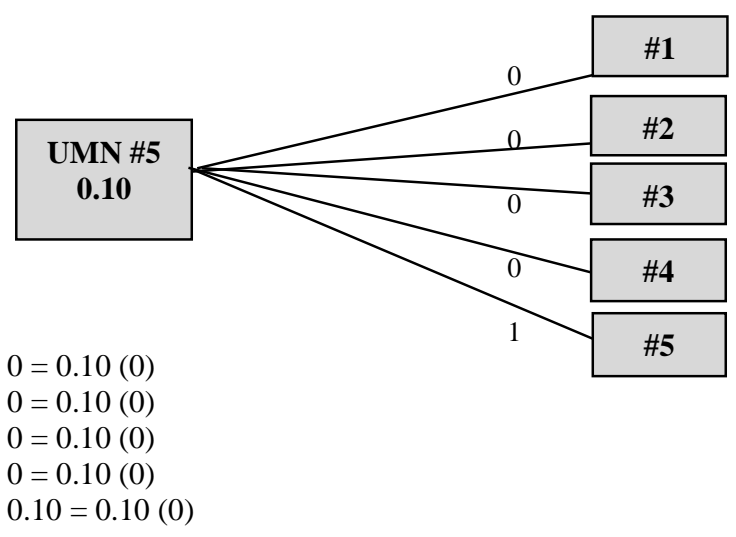

Perhitungan Manual Pendugaan Pangsa

Pasar Periode Berikutnya

Berdasarkan pada data yang telah dikumpulkan, maka pendugaan peminatan pada kelima universitas favorit siswa Madrasah Aliyah Al-Islamiyah di Jakarta Barat untuk periode berikutnya adalah sebagai berikut:

\begin{tabular}{|c|c|c|c|c|c|}
\hline \multicolumn{6}{|c|}{$\pi(1)=\pi(0) \mathrm{P}$} \\
\hline Permintaan & \multicolumn{5}{|c|}{$\begin{array}{l}\text { Matriks transisi } \\
\text { probabilitas }\end{array}$} \\
\hline$P=(0.41,0.05,0.31,0.13,0.10)=$ & 1 & 0 & 0 & 0 & 0 \\
\hline & 0 & 1 & 0 & 0 & 0 \\
\hline & 0.25 & 0.08 & 0.67 & 0 & 0 \\
\hline & 0.2 & 0.2 & 0 & 0.6 & 0 \\
\hline & & 0 & 0 & 0 & 0 \\
\hline
\end{tabular}

$P=(0.5135,0.1008,0.2077,0.078,0.1)$
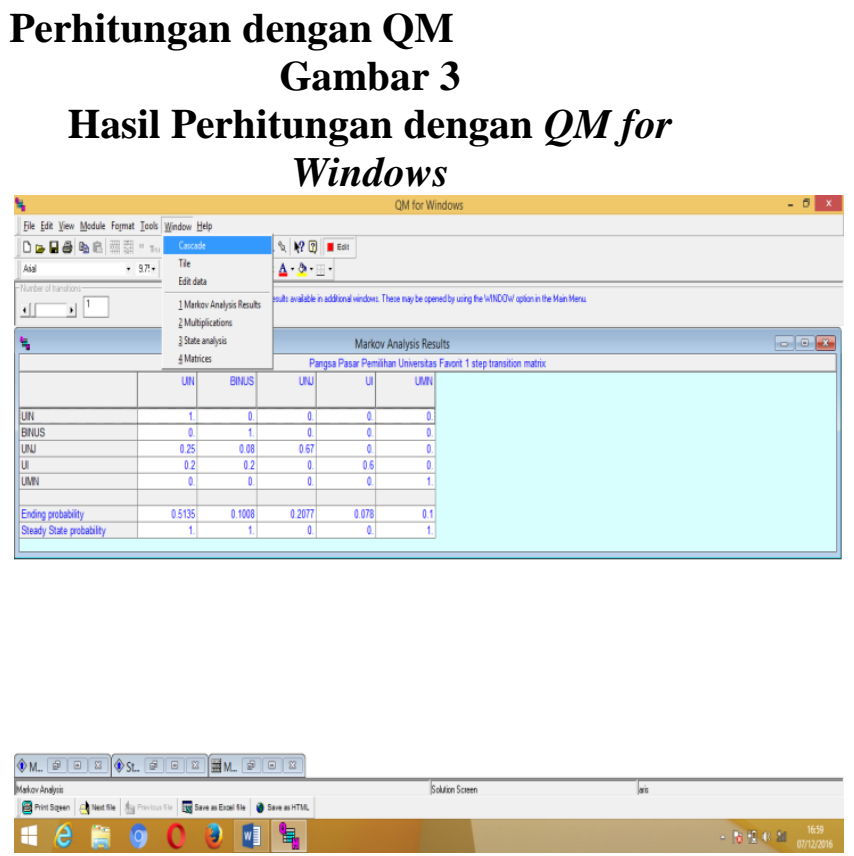

Sumber: QM for Windows (2016)

Berdasarkan kuesioner yang diisi oleh 39 responden, pendugaan pangsa pasar pemilihan universitas favorit siswa Madrasah Aliyah Al-Islamiyah pada periode berikutnya adalah Universitas Islam Negeri (UIN) 0.5135, Universitas Bina Nusantara (UBinus) 0.1008, Universitas Negeri Jakarta (UNJ) 0.2077, Universitas Indonesia (UI) 0.078, Universitas Multimedia Nusantara (UMN) 0.1. Pangsa pasar terbesar dimiliki oleh Universitas Islam Negeri (UIN) yaitu sebesar 0.5135, sedangkan pangsa pasar terkecil dimiliki oleh Universitas Indonesia (UI) yaitu sebesar 0.078. 
Pengujian Validitas dan Reliabilitas

Tabel 11

Hasil Pengujian Validitas Variabel

\begin{tabular}{|c|c|c|c|c|c|}
\hline $\begin{array}{c}\text { Item } \\
\text { Pernya } \\
\text { taan }\end{array}$ & $\begin{array}{c}\mathbf{r} \\
\text { hitung }\end{array}$ & $\begin{array}{c}\mathbf{r} \\
\text { table }\end{array}$ & $\begin{array}{l}\text { Kepu } \\
\text { tusan }\end{array}$ & $\begin{array}{l}\text { Cronbach's } \\
\text { Alpha }\end{array}$ & $\begin{array}{c}\text { Keputu } \\
\text { san }\end{array}$ \\
\hline P1 & 0.340 & 0.27 & Valid & \multirow{15}{*}{0.823} & \multirow{15}{*}{ Reliable } \\
\hline P2 & 0.496 & 0.27 & Valid & & \\
\hline P3 & 0.328 & 0.27 & Valid & & \\
\hline $\mathrm{P} 4$ & 0.317 & 0.27 & Valid & & \\
\hline P5 & 0.496 & 0.27 & Valid & & \\
\hline P6 & 0.540 & 0.27 & Valid & & \\
\hline P7 & 0.426 & 0.27 & Valid & & \\
\hline P8 & 0.306 & 0.27 & Valid & & \\
\hline P9 & 0.439 & 0.27 & Valid & & \\
\hline P10 & 0.583 & 0.27 & Valid & & \\
\hline P11 & 0.582 & 0.27 & Valid & & \\
\hline P12 & 0.450 & 0.27 & Valid & & \\
\hline P13 & 0.376 & 0.27 & Valid & & \\
\hline P14 & 0.620 & 0.27 & Valid & & \\
\hline P15 & 0.357 & 0.27 & Valid & & \\
\hline
\end{tabular}

Sumber: SPSS (2016)

\section{SIMPULAN}

Setelah melakukan penelitian dan analisis dari Madrasah Aliyah Al-Islamiyah di Jakarta Barat, maka dapat ditarik simpulan sebagai berikut. Terdapat 5 universitas favorit, yaitu Universitas Islam Negeri, Universitas Bina Nusantara, Universitas Negeri Jakarta, Universitas Indonesia dan Universitas Multimedia Nusantara. Prediksi peminatan pada periode berikutnya adalah peminat Universitas Islam Negeri 0.5135, peminat Universitas Bina Nusantara adalah 0.1008, peminat Universitas Negeri Jakarta adalah 0.2077, peminat Universitas Indonesia adalah 0.078, peminat Universitas Multimedia Nusantara adalah 0.1. Berdasarkan hasil analisis, pangsa pasar terbesar dimiliki oleh peminat Universitas Islam Negeri yaitu sebesar 51\%, sedangkan pangsa pasar terkecil dimiliki oleh peminat Universitas Indononesia yaitu sebesar $8 \%$.

Berdasarkan kuesioner yang diisi oleh 39 responden maka dapat ditarik kesimpulan bahwa penilaian terbesar siswa dalam memilih universitas favorit mereka adalah 0.62 responden memlilih universitas favorit karena citra universitas (brand image), 0.583 responden memperoleh referensi dari event promosi universitas yang dilakukan oleh universitas tersebut, 0.582 responden memperoleh referensi dari teman, dan 0.54 responen memilih universitas favorit karena keamanan di lingkungan universitas. Berdasarkan hasil analisis, sumber referensi terbesar bagi responden dalam memilih universitas yang diminati yaitu berasar dari citra universitas (brand image) 0.62.

\section{SARAN}

Saran yang diberikan dalam penelitian ini adalah sebagai berikut. Setelah melakukan analisis, peneliti memberikan saran dan masukan agar hasil analisis dapat dimanfaatkan. Adapun saran-saran yang diberikan adalah sebagai berikut.

1. Sumber referensi yang paling tinggi dalam pemilihan universitas favorit berasal dari citra universitas (brand image), disarankan kepada para universitas untuk meningkatkan program pendidikan berkualitas, memberikan variasi program studi, dosen berkualitas, status dan akreditasi 
diakui, meningkatkan dalam hal fasilitas perkuliahan dan sarana lainnya.

2. Para universitas dapat melakukan perbaikan dan peningkatan dalam hal promosi, fasilitas perkuliahan, lokasi universitas yang strategis, biaya kuliah yang terjangkau dan brand image.

3. Para universitas dapat lebih meningkatkan media pemasaran yang dilakukan, seperti melalui iklan dan event promosi untuk dapat menarik konsumen yang lebih besar agar pangsa pasar atau peminat yang dimiliki oleh universitas juga semakin besar, karena sumber referensi pelajar dalam memilih universitas yang mereka minati sebagian besar berasal dari iklan dan event promosi pada universitas.

\section{DAFTAR PUSTAKA}

Adam, Muhammad. 2015. Manajemen Pemasaran Jasa Teori dan Aplikasi. Alfabeta, Bandung.

Alma, Buchari dan Hurriyati, Ratih. 2009. Manajemen Corporate dan Strategi Pemasaran Jasa Pendidikan Fokus Pada Mutu dan Pelayanan Prima. Cet.2. Alfabeta, Bandung.

Asra, Abuzar, dkk. 2015. Metode Penelitian Survei. In Media, Bogor.

Damalita, Susiasih. 2009. Pentingnya Manajemen Arsip di Lingkungan Perguruan Tinggi. Jurnal Ekonomi, Manajemen dan Bisnis Vol.3, No.1, Desember 2009.

David, R. Fred. 2010. Manajemen Strategis Konsep. Buku 1, Edisi 12. Salemba Empat, Jakarta.
Feriyanto, Andri dan Triana, S. Endang. 2015. Pengantar Manajemen (3 in 1). Media Tera, Kebumen.

Herdiana, Nana A. 2015. Manajemen Strategi Pemasaran. CV. Pustaka Setia, Bandung.

Irianto, B. P. Aloysius. 2015. Pemanfaatan Social Media untuk Meningkatkan Market Share UKM. Jurnal Teknomatika Vol. 8, No. 1, Juli 2015. Marwanto, Aris. 2015. Marketing Sukses. Cet.1, Kobis, Yogyakarta.

Maulidah, Silvana. 2010. Struktur Pasar Minyak Kayu Putih. Jurnal Manajemen Pemasaran, Vol.5, No.1, April 2010.

Muhardi, 2011. Manajemen Operasi Suatu Pendekatan Kuantitatif untuk Pengambilan Keputusan. Refika Aditama, Bandung.

Noer, A. Bustanul. 2010. Belajar Mudah Riset Operasional. Ed. 1. Andi, Yogyakarta.

Nursanti, D. Tinjung, dkk. 2010. Pemilihan Universitas Favorit dengan Pendekatan Rantai Markov. Jurnal Binus Business Review Vol. 1. No. 2, November 2010, Hal. 363-377.

Peter, Paul J. dan Olson, Jerry C. 2013. Perilaku Konsumen dan Marketing Strategy. Buku 1, Edisi 9. Salemba Empat, Jakarta.

Putri, Melsi D. 2014. Model Hidden Markov Pada Prediksi Harga Beras di Kota Solok Provinsi Sumatra Barat. Jurna Eksakta, Vol.1 Tahun XV Februari 2014.

Ridhotullah, Subeki dan Jauhar, Mohammad. 2015. Pengantar Manajemen. Cet.1. Prestasi Pustakaraya, Jakarta.

Sarjono, Haryadi. 2010. Aplikasi Riset Operasi. Salemba Empat, Jakarta. 
Sarjono, Haryadi dan Julianita, Winda.

2011. SPSS VS LISREL. Jakarta.

Salemba Empat.

Sugiyono. 2014. Metode Penelitian

Kuantitatif Kualitatif dan $R \& D$.

Alfabeta, Bandung.

Sujarweni, Wiratna V. 2014. Metodologi Penelitian. Cet 1. Pustaka Baru Press, Yogyakarta.

Sunyoto, Danang dan Susanti, E. Fathonah. 2015. Manajemen Pemasaran Jasa. Cet.1, Yogyakarta.

Susanto, A. B. 2014. Manajemen Strategik Komprehensif. Erlangga.

Terry, R. George dan Rue, W. Leslie. 2014. Dasar-Dasar Manajemen. PT. Bumi Aksara, Jakarta.

Tjiptono, Fandy. 2015. Strategi Pemasaran.

Edisi 4. CV. Andi, Yogyakarta.

Widiasanti, Irika dan Lenggogeni. 2014.

Manajemen Konstruksi. Cet.2. PT.

Remaja Rosdakarya, Bandung.

Winarno, dkk. 2015. Faktor-Faktor yang

Memengaruhi

Profitabilitas

Perusahaan Manufaktur yang Listed di

Bursa Efek Indonesia. Jurnal

Economia, Vol. 11, No. 2, Oktober 2015.

www.kompasiana.com/rachmayanirina

www.pendis.kemenag.go.id 
